\title{
THE USE OF SIRE AND DAM FAMILY AVERAGES IN INCREASING THE EFFICIENCY OF SELECTIVE BREEDING UNDER A HIERARCHICAL MATING SYSTEM
}

\author{
R. OSBORNE \\ Poultry Research Centre, Edinburgh, Scotland
}

Received I5.ii.5f

\section{INTRODUCTION}

THE relative merits of individual selection and family selection in breeding for traits of incomplete heritability were first discussed by Lush (1947) and, more recently, with particular reference to poultry breeding, by Lerner (1950). The general conclusion is that for traits of low heritability, selection of complete families of full or half-sibs without regard to individual performance is more efficient than selection on the basis of individual phenotypes. For higher values of heritability the situation may be reversed, but in all cases maximum efficiency can be obtained by selection on the basis of a combination of family average and individual record.

In poultry and other animal populations the family classification is a hierarchical one, consisting of several sires each mated to a number of dams and each mating producing several offspring. Various schemes of family selection or combination selection are thus available:

(I) Selection of complete full-sib families disregarding any classification into half-sib families, i.e. selection on the basis of dam family average without regard to sire family average or individual merit.

(2) Selection on the basis of an index with particular weights attached to the full-sib family averages and to individual records.

(3) Selection of complete sire families alone, each sire family consisting of a mixture of full- and half-sibs.

(4) Selection on the basis of an index with particular weights attached to sire family averages, dam family averages, and individual records.

The first and second of these systems are discussed in detail by Lerner (1950, ch. XI) but neither of the others have been investigated, the nearest approach being the comparisons by Lerner and Lush of the relative merits of mass selection and half-sib family selection. These comparisons, however, neglect the full-sib relationship which exists between many pairs of a half-sib group in the above hierarchy.

It is evident that the first three of the above systems are particular 
cases of the fourth-systems (I) and (2), for example, correspond to cases where zero weight is attached to the sire average-and hence that the efficiency of system (4) must always be greater than or equal to that of the others. One object of this investigation was thus to assess the optimum weighting factors applicable under system (4) and the increase in efficiency of selection attainable thereby. Secondly, it was judged of major importance to assess the relative efficiency of system (3)-selection of sire families alone, particularly in view of the drastic reductions in labour of individual recording which the system may permit.

System (3) may in fact be regarded as a modified "Hagedoorn Nucleus System ". This system of poultry breeding (Hagedoorn and Sykes, I953) involves the selection of complete sire families without individual recording, followed by brother $\times$ sister or half brother $\times$ sister mating within the selected groups. Whilst the well-known deterioration of most production traits under inbreeding, coupled with the lowered selection differential available, throws serious doubts on the eventual outcome, it is shown here that the system of family selection is basically sound and can readily be adapted to a noninbreeding scheme (paradoxically it must be noted that the theoretical efficiency of the method rests on the concept of heritability, summarily dismissed by Hagedoorn as unscientific). Adaptation of the method to a non-inbreeding scheme appears in fact to have been carried out by Sykes (1953), who obtained quite marked increases in egg production over a short test of three years (Hagedoorn and Sykes, p. 202). Likewise, Hagedoorn (pp. 65-66) claims similar success in the breeding of Khaki Campbell ducks by Jansen, but from the discussion by Hutt (I952) it seems clear that emphasis has been placed on the selection of progeny tested males, and also that individual recording of females has been the rule.

It would be premature to advocate without reservation Hagedoorn's recommendation that individual recording can be completely dropped in favour of recording families housed as units. Environmental effects peculiar to pens or units may preclude the recognition of true genetic differences, although in poultry there is some evidence (Dudley and Read, I949; Hale, I952) that uncontrollable variations between pens treated alike will be unimportant in this respect. However, even with individual recording under randomised environmental conditions it is important to note the value of the sire family average in a selection programme, since for traits of low heritability the greatest weight is to be attached to this parameter. Likewise, even with individuals housed at random, system (3) affords a much simplified system of recording, identification of, say, egg production being necessary only on a family basis with coloured leg bands being sufficient to identify the family to which an individual belongs. Such recording could be supplemented by individual information either from recording or handling as available. 


\section{THEORY}

\section{(i) Basic concepts}

The principles of family and individual selection originate in the statistical studies of Fisher (I9I8) and Wright (I92I), placed on an applied basis by Lush (I945, I947) with particular emphasis on Wright's concept of heritability.

The simplest assumption in dealing with the inheritance of quantitative characteristics in this context is that phenotypic differences arise from the joint effect of independent and additive differences in genotype and individual environment. If environmental factors operate at random the phenotypic variance $\sigma^{2}{ }_{P}$ may be expressed as the sum of two parts, $\sigma_{G}^{2}$ and $\sigma_{E}^{2}$, reflecting respectively the variance due to these agencies. Heritability, or the proportion of variance due to genetic differences, may then be expressed as $h^{2}=\frac{\sigma_{G}^{2}}{\sigma_{G}^{2}}$.

The genetic value of an individual may be defined as the phenotypic value attained if subject to the average environment of the population, differences between genetic and actual phenotypic values being due to individual vagaries of environment. For prediction of gains from selection an estimate is required of the genetic value of individuals or groups selected on the phenotypic level. The population regression coefficient of genotype on phenotype is

$$
\frac{\operatorname{cov}(\mathrm{G}, \mathrm{P})}{\sigma^{2}{ }_{\mathrm{P}}}=\frac{\operatorname{cov}(\mathrm{G}, \mathrm{G}+\mathrm{E})}{\sigma^{2}{ }_{\mathrm{P}}}=\frac{\sigma^{2}{ }_{\mathrm{G}}}{\sigma^{2}{ }_{\mathrm{P}}}=h^{2}
$$

(where G, P, E represent deviations from means due to each agency). Thus, individuals whose phenotypic mean differs from that of the parental population by an amount I have an expected genetic deviation of $\mathrm{I} h^{2}$, this quantity representing the expected deviation of the mean of their offspring from that of the parental population, or the expected gain from individual selection, if the same selection pressure $I$ is applied to both male and female parents. If only females are selected the gain is $\frac{1}{2} \mathrm{I} h^{2}$ where $\mathrm{I}$ is measured in females only. The accuracy of such prediction in an individual sample or flock is, of course, higher the larger the sample; otherwise for small samples it can only be regarded with confidence as the average gain expected from repeated samplings and selections.

Heritability can be defined either on an individual or on a family basis. In the latter case $h_{\mathrm{F}}^{2}$ is the regression of family genetic mean on phenotypic mean and, since the individual effects of environment cancel out in the family mean, is greater than $h^{2}$. The gain from selection of complete families is $I_{F} h_{F}{ }_{F}$ where $I_{F}$, the selection differential, represents the deviation of the mean of selected families from the population mean. Since, except for certain limitations discussed later, a fixed proportion of the population is required for replacement whatever the criterion of selection, a more convenient nomenclature 
is to express the expected gains as gains per unit standard deviation in the selection differential. Thus, if $\sigma_{\mathrm{P}}$ is the phenotypic standard deviation of individuals, $\sigma_{\mathrm{F}}$ that of families, the gains from individual and family selection are $\Delta \mathrm{G}=h^{2} \sigma_{\mathrm{P}}$ and $\Delta \mathrm{G}_{\mathrm{F}}=h_{\mathrm{F}}{ }_{\mathrm{F}} \sigma_{\mathrm{F}}$. The lowered selection differential corresponding to the lowered variability of family averages counteracts the tendency for the increased heritability of family averages to enhance efficiency of selection.

The above examples are particular cases of the rule that where selection is based on an index $I$ the gain in character $P$ (again per unit standard deviation in the selection differential) is $\Delta \mathrm{G}_{\mathrm{I}}=\mathrm{R}_{\mathrm{IG}} \sigma_{\mathrm{G}}$ where $R_{\text {IG }}$ is the correlation between genotype and criterion of selection (cf. Lush, 1947, p. 247 ; Lerner, 1950, p. 164). For selection on phenotypic values of individuals $\mathbf{R}_{\mathrm{IG}}=h$ giving $\Delta \mathrm{G}=h \sigma_{\mathrm{G}}=h^{2} \sigma_{\mathrm{P}}$.

The present analysis is referred primarily to poultry populations where the main interest is centred on the production characteristics of a population of females. The efficiency of individual selection is taken as a basis for comparing the merits of different systems and since no criterion of individual merit may be available for selection of males the present comparisons are based throughout on the selection of females only. The principles of family selection may be readily extended to the selection of male parents on the performance of their full- and half-sisters, but to avoid unnecessary elaboration only the basic points will be mentioned here.

For selection of females a gain of Io eggs from individual selection may be magnified to 15 eggs when family average is the criterion of selection, whilst if equally efficient selection of males is carried out the latter figure will be doubled. Various complicating factors, however, will be introduced. Firstly, if family merit is the criterion, the accuracy of identifying male genotypes will be less than for females, since only in the latter case are the individual phenotypes included in the family average. Secondly, the actual gains from male selection depend on the number of males which can be retained for future breeding and their distribution by families. If small numbers are available, the choice may be restricted to families other than those providing the superior females, and the efficiency of selection reduced. Conversely, if large family groups of males are available the relatively small number necessary to replace the flock may be obtained from a more restricted group of families than that involved in the selection of females, the efficiency of male selection thereby being increased. Assuming, however, the efficiency of selection to be the same for both sexes the following results for family selection represent only half the possible gains.

For combination selection the further gain to be expected from selection of males will be offset by the fact that individual merit cannot be included in the index of selection. These points will be dealt with more adequately in subsequent studies; for the present it is sufficient to illustrate the relative merits of the systems for female 
selection alone. Throughout the paper gains will thus be referred to as $\frac{1}{2} \mathbf{I} h^{2}$ instead of the customary $\mathbf{I} h^{2}$ when the same selection pressure applies to both parents.

\section{(ii) Efficiency of family selection on systems (I) and (3)}

It is assumed in what follows that selection is from a population of s.d.n. offspring originating from $s$ sires each mated to $d$ dams and each mating producing $n$ offspring. The distribution of variance of offspring is then of the form in table $\mathrm{I}$, the model being that commonly used in estimation of heritability.

$\mathrm{Q}, \mathrm{D}$ and $\mathrm{S}$ are respectively the variance components associated with full-sibs, true means of dam families within sire groups, and true

TABLE I

Analysis of variance model for estimation of heritability

\begin{tabular}{|c|c|c|}
\hline Source of variation & Degrees of freedom & Expected mean square \\
\hline Between sires & $s-1$ & $\mathrm{Q}+n \mathrm{D}+n d \mathrm{~S}$ \\
\hline Between dams within sires & $s(d-\mathrm{I})$ & $\mathrm{Q}+n \mathrm{D}$ \\
\hline Between full-sibs . & $d s(n-\mathrm{I})$ & $Q$ \\
\hline
\end{tabular}

means of sire groups. It is readily shown (e.g. Comstock and Robinson, I948) that for random mating and additive autosomal inheritance, values of these components are

$$
\mathrm{Q}=\frac{1}{2} \sigma_{\mathrm{G}}^{2}+\sigma_{\mathrm{E}}^{2}, \mathrm{D}=\mathrm{S}=\frac{1}{4} \sigma_{\mathrm{G}}^{2} \text {. }
$$

Heritability in the infinite random bred population may then be defined as

$$
h^{2}=\frac{{ }_{4} \mathrm{~S}}{\mathrm{Q}+\mathrm{D}+\mathrm{S}}=\frac{{ }_{4} \mathrm{D}}{\mathrm{Q}+\mathrm{D}+\mathrm{S}}=\frac{2(\mathrm{D}+\mathrm{S})}{\mathrm{Q}+\mathrm{D}+\mathrm{S}}
$$

and may be estimated from sample values of components derived from actual mean squares. Alternatively the above ratios can be regarded as intra-class correlation coefficients, $S /(Q+D+S)$ for example representing the correction between half-sibs of $\frac{1}{4} h^{2}$.

Whilst the above model provides a valid estimate of heritability in the infinite random bred population it should be pointed out that for small samples a correction is, strictly speaking, necessary to the usual prediction of gain as $\frac{1}{2} \mathrm{I} h^{2}$. The closest estimate of gain is actually $\frac{1}{2} \mathrm{I} h^{2}{ }_{c}$ where $h^{2}{ }_{c}$ is the regression of genotype on phenotype in the population from which the parents are selected. The expectation of this regression is $G / P$ where $G$ and $P$ are the expected genetic and phenotypic variances (as the means of repeated sampling) of the 
s.d.n. offspring. Pooling of mean squares in table I gives

$$
\begin{aligned}
\mathrm{P} & =\mathrm{Q}+\frac{n(s d-\mathrm{I}) \mathrm{D}}{s d n-\mathrm{I}}+\frac{n d(s-\mathrm{I}) \mathrm{S}}{s d n-\mathrm{I}} \\
& =\sigma^{2}{ }_{\mathrm{E}}+\sigma_{\mathrm{G}}^{2}\left\{\frac{\mathrm{I}}{2}+\frac{n}{4}\left(\frac{s d-\mathrm{I}}{s d n-\mathrm{I}}\right)+\frac{n d}{4}\left(\frac{s-\mathrm{I}}{s d n-\mathrm{I}}\right)\right\} \\
\text { and } \mathrm{G} & =\mathrm{P}-\sigma_{\mathrm{E}}^{2} .
\end{aligned}
$$

The expected gain is thus $\frac{1}{2}(\mathrm{IG} / \mathrm{P})$. The utility of the correction for small samples is seen by assigning particular values to $s, d$, and $n$. Case $s=d=\mathrm{I}$ corresponds to selection from a single randomly chosen full-sib family giving, as required,

$$
P=\frac{1}{2} \sigma_{G}^{2}+\sigma_{E}^{2}, G=\frac{1}{2} \sigma_{G}^{2} \quad \text { (see also Section 2.iii). }
$$

Likewise $s=n=\mathrm{I}$ corresponds to selection from a single randomly chosen sire family where none of the half-sib progeny are full-sibs. Here

$$
\mathrm{P}=\frac{1}{2} \sigma_{\mathrm{G}}^{2}+\sigma_{\mathrm{E}}^{2}, \quad \mathrm{G}=\frac{3}{4} \sigma_{\mathrm{G}}^{2} .
$$

For large or even moderately sized populations the correction is small. It is greatest when $s$ and $d$ are small with $n$ large, when the full-sib relationship of individuals becomes important. For fixed $d$ and $n$ its importance declines as $s$ increases. It is assumed, therefore, in what follows, that $s$ is sufficiently large for the expectation of improvement to be taken as $\frac{1}{2} \mathrm{I} h^{2}$ or $\frac{1}{2} h^{2} \sigma_{\mathrm{p}}$.

(a) Selection of full-sib families. For full-sib families of size $n$ the expected phenotypic variance of the means of unrelated families is

$$
\mathrm{P}=\frac{\mathrm{Q}}{n}+\mathrm{S}+\mathrm{D}=\sigma_{\mathrm{G}}^{2} \frac{(n+\mathrm{I})}{2 n}+\frac{\sigma_{\mathrm{E}}^{2}}{n}
$$

and genetic variance $\mathrm{G}=\sigma_{\mathrm{G}}^{2} \frac{(n+\mathrm{I})}{2 n}$.

The expected gain $\Delta \mathrm{G}_{\mathrm{F}}=\frac{1}{2} h_{\mathrm{F}}^{2} \sigma_{\mathrm{F}}=\frac{1}{2}\left(\mathrm{G} / \mathrm{p} \frac{1}{2}\right)$ readily reduces to

$$
\frac{\frac{1}{2} h^{2} \sigma_{\mathrm{P}}(n+\mathrm{I})}{\sqrt{2 n\left\{2+(n-\mathrm{I}) h^{2}\right\}}} \text {. }
$$

and the efficiency of selection relative to individual selection is

$$
\frac{n+\mathrm{I}}{\sqrt{2 n\left\{2+(n-\mathrm{I}) h^{2}\right\}}}
$$

For the type of population involved here a correction is again necessary when $s$ is small because of the half-sib relationship existing between some families. The expected " between family" mean square (pooling of sires and dams within sires) is

$$
\mathrm{Q}+n \mathrm{D}+\frac{n d(s-\mathrm{I})}{s d-\mathrm{I}} \mathrm{S}
$$


the expected phenotypic variance of family means being

$$
\begin{aligned}
\mathrm{P} & =\frac{\mathrm{Q}}{n}+\mathrm{D}+\frac{d(s-\mathrm{I})}{s d-\mathrm{I}} \mathrm{S} \\
& =\sigma_{\mathrm{G}}^{2}\left\{\frac{\mathrm{I}}{2 n}+\frac{\mathrm{I}}{4}+\frac{(s-\mathrm{I}) d}{4(s d-\mathrm{I})}\right\}+\frac{\sigma^{2} \mathrm{E}}{n} \\
\text { and } \mathrm{G} & =\mathrm{P}-\frac{\sigma^{2} \mathrm{E}}{n} .
\end{aligned}
$$

Here again the correction is unimportant when, for fixed $n$ and $d$, $s$ is sufficiently large. Its importance is greatest when $s$ and $n$ are small and $d$ is large, when the half-sib relationship of full-sib families assumes importance. As before, $s$ is henceforward assumed to be sufficiently large for the efficiency of full-sib selection to be represented by (B), bearing in mind that it overestimates the efficiency for small samples.

(b) Selection of sire families (half- and full-sibs). Here the family size is $d n$, giving

$$
\begin{aligned}
\mathrm{P} & =\frac{Q}{d n}+\frac{\mathrm{D}}{d}+\mathrm{S} \\
& =\sigma_{\mathrm{G}}^{2}\left\{\frac{\mathrm{I}}{2 d n}+\frac{\mathrm{I}}{4 d}+\frac{\mathrm{I}}{4}\right\}+\frac{\sigma_{\mathrm{E}}^{2}}{n d},
\end{aligned}
$$

$\mathrm{G}$ being represented by the first term. Expectation of improvement comes to

$$
\Delta \mathrm{G}_{\mathrm{F}}=\frac{\frac{1}{2} h^{2} \sigma_{\mathrm{P}}\{2+n(\mathrm{I}+d)\}}{\sqrt{4 d n\left[4+\{n(\mathrm{I}+d)-2\} h^{2}\right]}} \quad \cdots \quad .
$$

and the efficiency relative to individual selection is

$$
\frac{2+n(\mathrm{I}+d)}{\sqrt{4 d n\left[4+\{n(\mathrm{I}+d)-2\} h^{2}\right]}}
$$

An alternative derivation is to use the fact that

$$
\Delta \mathrm{G}=\frac{\left\{\mathrm{I}+(n-\mathrm{I}) r_{\mathrm{G}}\right\} \frac{1}{2} h^{2} \sigma_{\mathrm{P}}}{\sqrt{n\left\{\mathrm{I}+(n-\mathrm{I}) r_{\mathrm{G}} h^{2}\right\}}} \quad .
$$

(Lush, I948, p. 248)

where $r_{G}$ is the genetic correlation between members of a family of size $n$. The average correlation between members of a sire family may be derived as

$$
\tilde{r}_{\mathrm{G}}=\frac{1}{4}\left\{\frac{n(d+\mathrm{I})-2}{n d-\mathrm{I}}\right\}
$$

by taking the correlation of full-sibs as $\frac{1}{2}$ and that of half-sibs as $\frac{1}{4}$. (This is the value of $\bar{r}_{G}$ applied erroneously by Garber and Godbey (I952) to correction of heritability estimates). Substitution of $\bar{r}_{G}$ for $r_{G}$ and $n d$ for $n$ in formula (E) gives formula (C). 
Putting $n=\mathrm{I}$ in (C) gives

$$
\Delta \mathrm{G}_{\mathrm{F}}=\frac{\frac{1}{2} h^{2} \sigma_{\mathrm{P}}(d+3)}{\sqrt{4 d\left\{4+(d-\mathrm{I}) h^{2}\right\}}}
$$

which may be readily deduced from first principles as the gain from selection of half-sib families, none of which are full-sibs.

It must be stressed that these relative gains will be approached with accuracy only for large populations. For small populations they correspond roughly to the average response from a series of selections but a further complication is introduced (particularly in sire family selection) by the reduction in selection differential caused by proportional selection from a small number of families. For an infinite population of families the selection differential for a selected

TABLE 2

Selection differentials and efficiency of selection for family selection when 20 per cent. of the families are required for replacement

\begin{tabular}{|c|c|c|c|}
\hline $\begin{array}{l}\text { Number of } \\
\text { families }\end{array}$ & $\begin{array}{c}\text { Number of } \\
\text { families selected }\end{array}$ & $\begin{array}{c}\text { Selection } \\
\text { differential }\left(I / \sigma_{F}\right) \text { for } \\
\text { 20 per cent. retained }\end{array}$ & $\begin{array}{l}\text { Efficiency of selection } \\
\text { relative to infinite } \\
\text { population }\end{array}$ \\
\hline $\begin{array}{c}5 \\
10 \\
20 \\
3^{0} \\
4^{0} \\
5^{\circ} \\
\text { Infinite }\end{array}$ & $\begin{array}{c}\text { I } \\
2 \\
4 \\
6 \\
8 \\
\text { I } 0 \\
\text { 20 per cent. }\end{array}$ & $\begin{array}{l}I \cdot I 6 \\
I \cdot 27 \\
I \cdot 33 \\
I \cdot 35 \\
I \cdot 36 \\
I \cdot 37 \\
I \cdot 40\end{array}$ & $\begin{array}{l}0.83 \\
0.91 \\
0.95 \\
0.96 \\
0.97 \\
0.98 \\
1.00\end{array}$ \\
\hline
\end{tabular}

proportion of 20 per cent. of the population is $\mathrm{I} \cdot 40 \sigma_{\mathrm{F}}$. For smaller groups of families the differential is reduced, 2 out of Io families giving an effective coefficient of only $\mathrm{I} \cdot 27 \sigma_{\mathrm{F}}$. This is derived from table XX in Fisher and Yates' (1948) tables which gives, for ranked data, the average deviation of the $r^{\text {th }}$ largest of samples of $n$ observations from a normal distribution. Nordskog and Wyatt (1952) give the appropriate selection differentials per unit standard deviation for a replacement fraction of 20 per cent. These are given in table 2, along with the corresponding efficiency of selection relative to that for an infinite population. Theoretically the correction is applicable to all types of selection-individual, full-sib and sire family, but its importance will be negligible in the first case and most serious in the third.

A statistical limitation on family size is described by Lerner (p. 278) for the case of full-sib selection. The foregoing formulæ assume that the proportion of the flock kept for replacement is the same for both individual and family selection. For full-sib selection this is only true if the number of individuals per family is less than the number of families. As an example, in a flock of 900 in 90 families of Io each, 90 individuals or Io per cent. of the flock are required for replacement with the same family size. With full-sib selection, 
9 families, again to per cent. of the flock, are required. Again, for family size of 30 , one family or 3.3 per cent. of the population must be selected and 3.3 per cent. with individual selection. However, if family size is 45 , only 20 individuals or $2 \cdot 2$ per cent. are required on individual selection, whereas the one full-sib family still selected on the family basis now comprises 5 per cent. of the population. Even if only a random sample of the selected family is taken for replacement, the reduction in selection differential and genetic gain is a necessary consequence. The limiting case for accuracy of the foregoing comparisons is that at least one (and an integral number) of sire families should be required for replacement. In sire family selection this imposes the restriction that the number of sire families should not be less than the number in a full-sib family. Thus, if the latter is Io, Io per cent. are required for selection of individuals; selection of a complete sire family, size $n d$, will still involve the same proportion if the population size is Iond, i.e. there are at least ro sire families.

Finally, the question of selecting integral numbers of sire families may assume some importance in small populations although not necessarily because of population size per se. If, for example, 6 sires are each mated to ro dams and each dam produces 4 offspring, the population size is 240 , and 60 individuals or 25 per cent. are required for replacement. In sire family selection the effective proportion of families selected, each containing 40 individuals, is 2 out of 6 or $33 \frac{1}{3}$ per cent., with a corresponding reduction in efficiency. On the other hand, this difficulty would not arise if the number of sire families were any multiple of 4 since then 25 per cent. of the families would always be selected.

The errors introduced in these respects become unimportant for large values of $s$ as do the corrections to individual and full-sib selection described earlier. Under such circumstances the relative efficiencies of full-sib and sire family selection are given by (B) and (D) as

$$
\frac{n+\mathrm{I}}{\sqrt{2 n\left\{2+(n-\mathrm{I}) h^{2}\right\}}} \text { and } \frac{2+n(\mathrm{I}+d)}{\sqrt{4 d n\left[4+\{n(\mathrm{I}+d)-2\} h^{2}\right]}}
$$

(c) Comparison of gains. Probably the most useful measure of improvement in egg production of poultry is the production index or egg production (individual or average) of all birds housed, regardless of mortality. The number of estimates of its heritability are very limited, though for the University of California flock an estimate in the region of 0.05 appears to be reliable (Dempster and Lerner, 1947 ; Lerner and Hazel, I947; Lerner, I950, pp. I25-128). King and Henderson (1954) obtained an estimate in the region of $0 \cdot 20$, but this increase was due to a statistical correction for date of hatch, heritability being estimated on a within-hatch basis on the assumption that no interactive effects with date of hatch are present.

Viability, closely associated with the production index, is also of low heritability. Lush, Lamoreux and Hazel (r948) obtained an 
estimate of 0.083 for adult mortality whilst Robertson and Lerner (1949) reported a figure of o.089. For mortality from lymphomatosis the comparable estimates were 0.059 and 0.048 . A value of 0.026 was found by Robertson and Lerner for mortality from reproductive disorders. Hale (1954) found a heritability of 0.07 for chick viability, the correspondence of these estimates from various sources suggesting that values less than $0 \cdot 10$ may be the general rule.

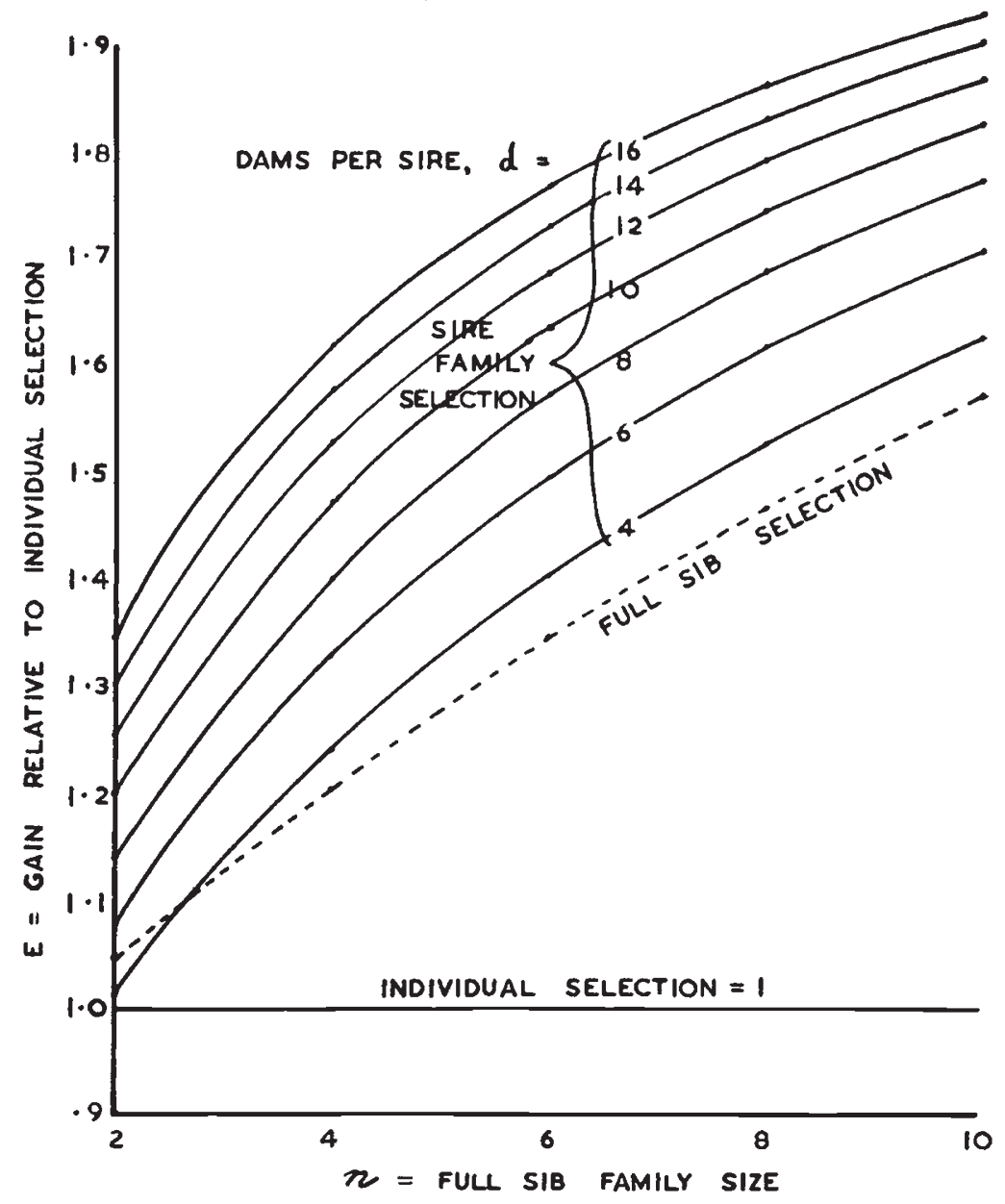

FIG. 1.-Efficiencies of selection of full-sib families and sire families relative to that of individual selection $\left(h^{2}=0 \cdot 05\right)$.

Lerner (1950. p. I25) gives a list of other production characteristics - sexual maturity, winter pause, rate, persistency, egg size and survivors' production-all with heritability less than 0.125 . As evident from a table of estimates in Jull (1952, p. 368) some of these must be regarded as under-estimates, but it is evident that particular attention should be paid to the applicability of formulæ (B) and (D) for heritabilities in the region of, say, zero to $0 \cdot 20$.

Figs. I to 3 show the relative efficiency of full-sib and sire family 
selection for $h^{2}=0.05,0.10,0.20$. The abscissæ represent $n$, the number of offspring per full-sib family, and the ordinates $E$, the efficiency of selection relative to individual selection. The relative

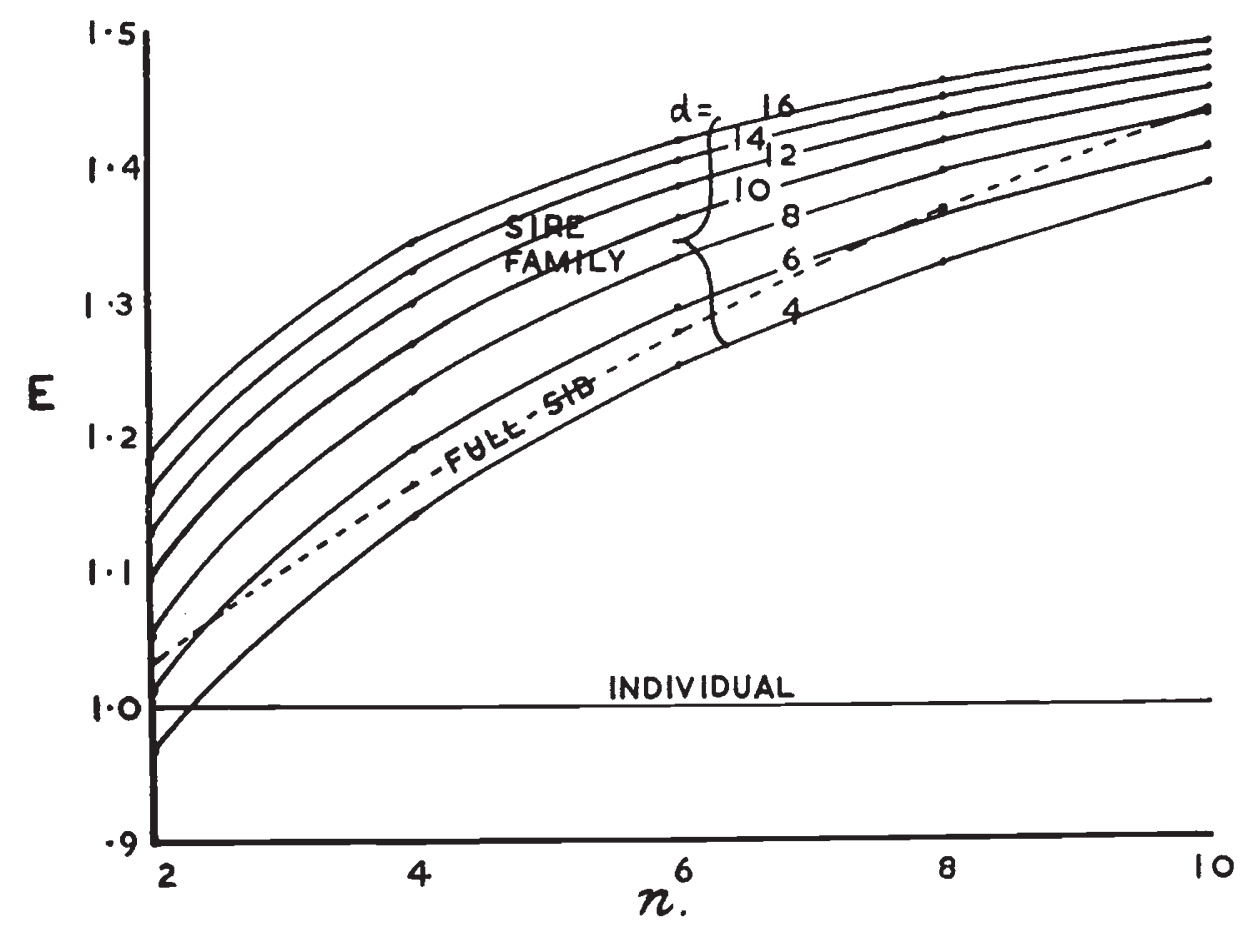

FIg. 2.-As fig. I for $h^{2}=0 \cdot 10$.

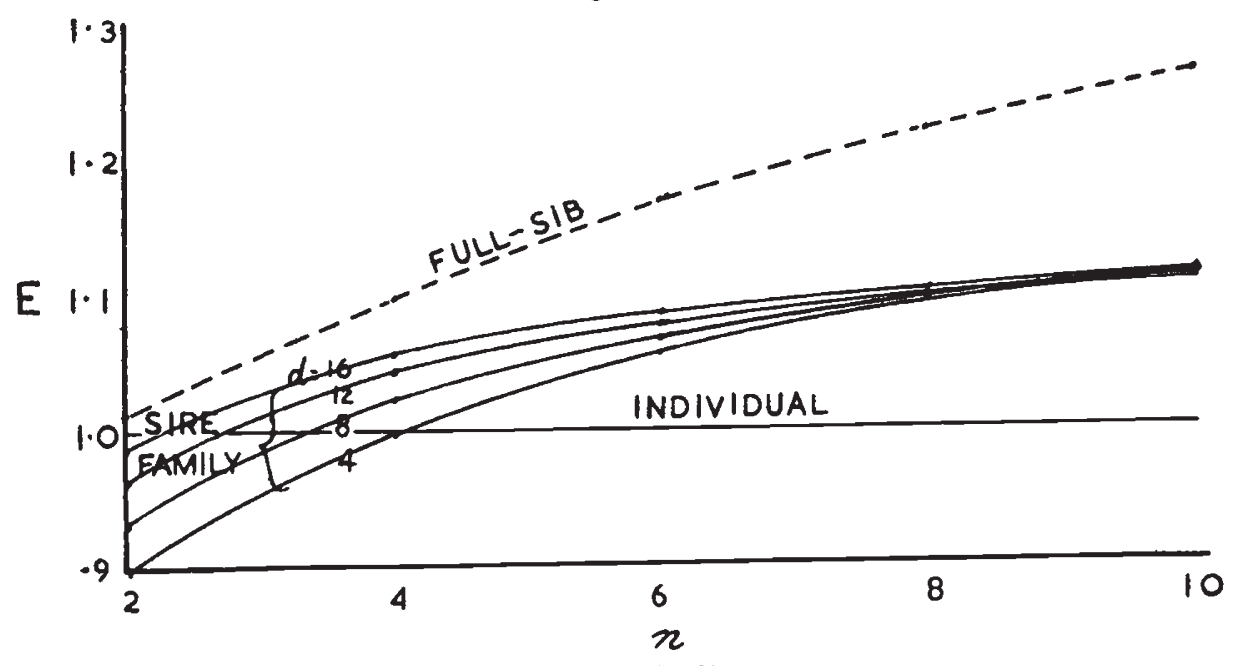

Fig. 3.-As fig. I for $h^{2}=0 \cdot 20$.

increase in efficiency of sire family selection over individual selection or full-sib selection is strikingly apparent for the lowest value of heritability of $0 \cdot 05$, its advantage declining with increase of the latter, until, at $h^{2}=0 \cdot 20$, the method is inferior to full-sib selection for all 
values of $n$ and $d$ appropriate to these graphs. However, as shown later, even at these higher levels the weight to be attached to the sire family average in a combined index is still high.

At $h^{2}=0.05$ " sire selection" is better than individual selection for all cases plotted and is better than full-sib selection except for the isolated case $d=4, n=2$. For $h^{2}=0 \cdot 10$ sire selection is better than individual selection except for $d=4, n=2$. If $d \geqslant 6$ it is again on the whole more efficient than full-sib selection, the exceptional cases being $d=6, n<3$ or $n>8 ; d=8, n \geqslant 10$. It is, however, apparent that the relative advantage declines rapidly with increasing $h^{2}$, as does the advantage of large values of $d$. At $h^{2}=0.20$ the approach to coincidence of the curves for different values of $d$ is apparent and sire selection is less efficient than full-sib selection; its overall advantage over individual selection, though small, is nevertheless still present except for $d=4, n<4 ; d=8, n<4 ; d=12$, $n=2 ; d=16, n=2$.

Several points regarding these graphs require to be emphasised. From fig. I, if $n=2$ the gain from full-sib selection relative to individual selection is $1 \cdot 05$, an increase of 5 per cent. The gain from sire family selection relative to individual selection for $n=2, d={ }_{1} 6$ is $\mathrm{I} \cdot 35$, an increase of 35 per cent. or 7 times the relative gain from full-sib selection (actually $7 \cdot 19$ ). At $n=$ ro the appropriate value has been reduced from $7 \cdot 19$ to $1 \cdot 63$. This is illustrated in fig. 4 (deducible from fig. I) where the ordinate $G$ represents the ratio of the percentage gain from sire selection over individual selection to the percentage gain from sib selection over individual selection. In an average case $n=6, d=12$ the value of the ratio is approximately 2 (actually $I \cdot 98$ ). This corresponds to the values from fig. I of $1 \cdot 347$ for the efficiency of full-sib selection and $\mathrm{I} \cdot 688$ for the efficiency of sire family selection.

The above, however, is not to be interpreted as a case for family selection with small rather than large full-sib families. The lower the number of offspring per breeding dam, the greater is the proportion of the flock necessary for replacement, with a consequent drop in absolute efficiency of individual or family selection. Case $n=10$ corresponds to a percentage of 10 necessary for replacement ; for a standardised normal distribution the normal deviate is $x=\mathrm{I} \cdot 28 \mathrm{I} 6$, the ordinate at this point $z=0.1753$ and the mean of the selected group is $z / q=\mathrm{I} \cdot 753$ ( $q=$ percentage selected). If $n=2$ the mean of the 50 per cent. selected is reduced to 0.798 with a corresponding reduction of gain from individual selection. In this respect the most useful graphs are those of fig. 5 where the gain from individual selection with $n=2$ is taken as unity and heritability is 0.05 . The lower curve represents the gain from individual selection with different family sizes computed from statistical tables on the above basis, the second the gain from full-sib selection, and the higher curves the gains from sire selection for different values of $d$. 


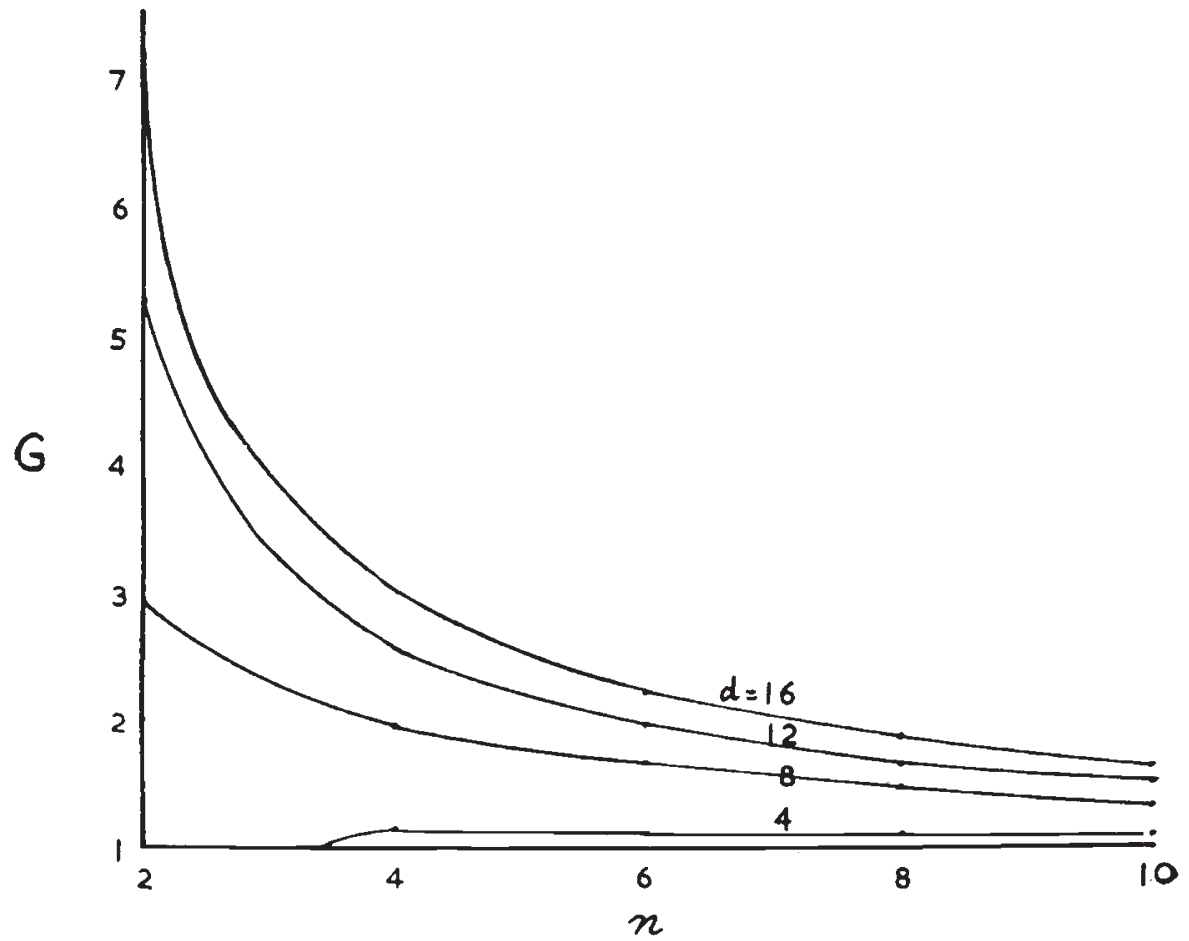

FIG. 4.-G, the ratio of the percentage gain from sire selection over individual selection to the percentage gain from sib selection over individual selection $\left(h^{2}=0.05\right)$.

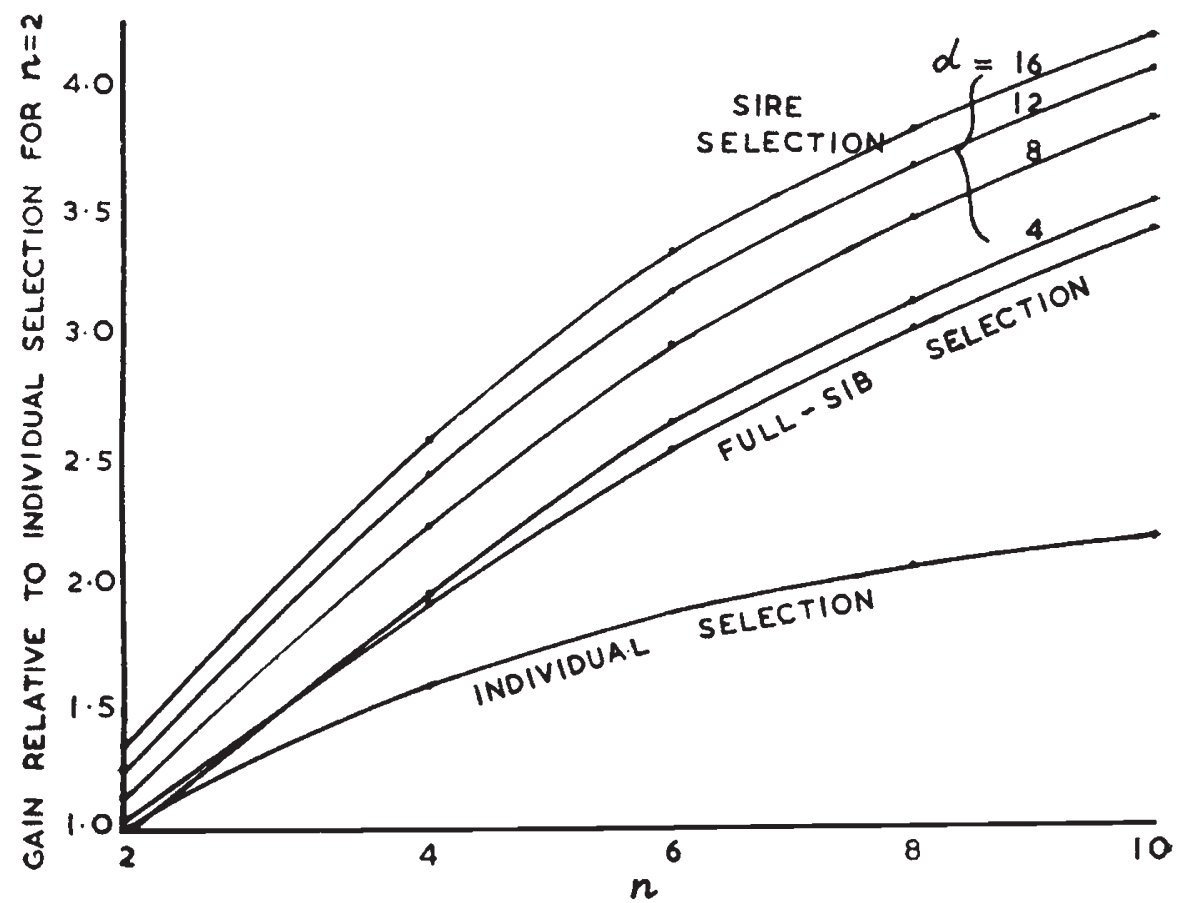

Frg. 5.-Efficiencies of individual selection, full-sib selection and sire family selection, relative to that of individual selection for $n=2\left(h^{2}=0.05\right)$. 
For most of the cases illustrated maximum increases are obtained with maximum $d$ so that in so far as flock size can be increased by increasing $d$ so is the efficiency of sire selection (relative and absolute) increased. In general $d$ will be determined by the mating limitations of the male parent and also by $n$, since the latter determines the total number of females necessary for replacement. The obvious and commonsense interpretation of the graphs is that (barring complications due to extension of the breeding season and the statistical limitation described previously) maximum gains from individual or family selection are obtained by increasing $n$. This determines $s d$, the number of selected females, whilst the greatest efficiency of sire selection is obtained by maximising $d$ and minimising $s$. All effects are thus cumulative; although the preceding results are referred to selection of females only, a minimal value of $s$ will further correspond to a greater intensity of selection of males.

A further point so far as poultry are concerned is that complications introduced by date of hatch render inadvisable an indiscriminatory increase in family size. Lerner (1950, p. 276) discusses the problem in terms of the reduction of heritability expected by increase of environmental variability occasioned by extension of hatching season. On the other hand, Osborne (1954a) has described an increase in the heritability of age at maturity occasioned by such extension, genetic variability being only apparent between individuals subject to greater extremities of climatic variation. Likewise, interactions of genotype and environment for the same characteristic reported by Osborne (I952) have since been reported by Skaller and Sheldon (1955). In 4 out of 5 flocks investigated by the latter authors, interaction significant at the ro per cent. or higher point was found between sire genotypes and date of hatch. Worthy of further investigation is the unsubstantiated claim by Skaller and Sheldon that "it is doubtful whether large errors would result from the application of present correction methods" (for linear changes in production characteristics occasioned by date of hatch). However, for short hatching season and values of $n$ normally found in practice, say $n=5$, the plotted values of efficiency may be regarded with confidence, the optimum value of $n$ being a subject demanding further investigation.

Another error, whose importance is yet subject to investigation, will be introduced for characteristics involving mortality, where the number per family at the selection stage differs from the original number on which heritability estimates are based. Actually the error would appear to operate by underestimating the efficiency of family selection since this system will almost certainly (in traits such as egg production) involve selection of superior members of superior families, the system becoming effectively selection on a combination of family average and individual merit.

It is finally to be noted that the relative efficiencies are unaffected 
by varying family size provided $n$ and $d$ are replaced by their average values calculated in the appropriate manner (e.g. Anderson and Bancroft, I952; Osborne, I $\left.954^{b}\right)$. In general arithmetic averages should provide a sufficiently good approximation.

\section{(iii) Combination selection under system (4)}

Here it is required to estimate the genetic value $G$ (estimate $\hat{G}$ ) of an individual in terms of phenotype $P$, dam family average $F_{D}$, and sire family average $F_{s}$. As a deviation from $G$, the population mean,

$$
\hat{\mathrm{G}}-\overline{\mathrm{G}}=\left(\hat{\mathrm{G}}-\mathrm{G}_{\mathrm{D}}\right)+\left(\mathrm{G}_{\mathrm{D}}-\mathrm{G}_{\mathrm{s}}\right)+\left(\mathrm{G}_{\mathrm{s}}-\overline{\mathrm{G}}\right),
$$

the deviation being expressed as the sum of three independent parts :

(I) the deviation of estimated genetic value from the genetic mean of the dam family;

(2) that of the dam family genetic mean from the sire family genetic mean ;

(3) that of the sire family genetic mean from the population genetic mean.

$\left(\hat{G}-G_{D}\right)$ may be expressed in the customary form for regression of genotype on phenotype

$$
\hat{\mathrm{G}}-\mathrm{G}_{\mathrm{D}}=h_{1}{ }^{2}\left(\mathrm{P}-\mathrm{F}_{\mathrm{D}}\right)
$$

where $h_{1}{ }^{2}$ is the effective heritability within full-sib families. Likewise

$$
\mathrm{G}_{\mathrm{D}}-\mathrm{G}_{\mathrm{S}}=h_{\mathrm{2}}{ }^{2}\left(\mathrm{~F}_{\mathrm{D}}-\mathrm{F}_{\mathrm{S}}\right)
$$

where $h_{\mathbf{2}}{ }^{2}$ is the heritability of full-sib averages within sire families, and finally

$$
\mathrm{G}_{\mathrm{s}}-\overline{\mathrm{G}}=h_{\mathbf{3}}{ }^{2}\left(\mathrm{~F}_{\mathrm{s}}-\overline{\mathrm{P}}\right)
$$

where $h_{3}{ }^{2}$ is the heritability of sire family averages ( $c f$. Lush, 1947, p. 259, and Robertson, I955).

Since $\left(\mathbf{P}-\mathbf{F}_{\mathbf{D}}\right)$ is measured from the sample family mean the effective phenotypic variance within dam families (see table $\mathrm{I}$ ) is

$$
{\sigma_{1}}^{2}=\frac{n-\mathbf{I}}{n} \cdot \mathrm{Q}=\frac{n-\mathbf{I}}{n}\left\{\frac{1}{2} \sigma_{\mathrm{G}}^{2}+\sigma_{E}^{2}\right\}
$$

and genetic variance $\sigma_{1}{ }^{2} \mathrm{G}=\frac{n-\mathrm{I}}{n} \cdot \frac{1}{2} \sigma_{\mathrm{G}}^{2}$.

Thus

$$
h_{1}^{2}=\frac{{\sigma_{1}{ }^{2}}_{\sigma_{1}}{ }^{2}}{\sigma^{2}}=\frac{\frac{1}{2} \sigma_{G}^{2}}{\frac{1}{2} \sigma_{G}^{2}+\sigma_{E}^{2}}=\frac{h^{2}}{2-h^{2}} .
$$

For means of dam families within sire families the phenotypic variance is

$$
{\sigma_{2}}^{2}=\frac{d-\mathrm{I}}{d}\left\{\frac{\mathrm{Q}}{n}+\mathrm{D}\right\}=\frac{d-\mathrm{I}}{d}\left\{\frac{\sigma_{\mathrm{G}}^{2}}{2 n}+\frac{\sigma^{2}}{n}+\frac{\sigma_{\mathrm{G}}^{2}}{4}\right\}
$$

and genetic variance $\sigma_{2}{ }^{2} \mathrm{G}=\frac{d-\mathrm{I}}{d}\left\{\frac{\sigma_{\mathrm{G}}{ }^{2}}{2 n}+\frac{\sigma_{\mathrm{G}}{ }^{2}}{4}\right\}$,

giving

$$
h_{2}^{2}=\frac{h^{2}(n+2)}{4+(n-2) h^{2}} \text {. }
$$


Similarly $h_{3}{ }^{2}=\frac{\left\{\frac{\sigma_{G}^{2}}{2 n d}+\frac{\sigma_{G}^{2}}{4 d}+\frac{\sigma_{G}^{2}}{4}\right\}}{\left\{\frac{\sigma_{G}^{2}}{2 n d}+\frac{\sigma^{2}}{n d}+\frac{\sigma_{G}^{2}}{4 d}+\frac{\sigma_{G}^{2}}{4}\right\}}=\frac{h^{2}\{n(\mathrm{I}+d)+2\}}{4+\{n(\mathrm{I}+d)-2\} h^{2}}$.

Thus the weighted function for optimum estimation of genetic values and hence for efficiency of selection is

$$
\begin{aligned}
\mathrm{I}=\hat{\mathrm{G}}-\mathrm{G}=\frac{h^{2}}{2-h^{2}}\left(\mathrm{P}-\mathrm{F}_{\mathrm{D}}\right)+\frac{h^{2}(n+2)}{4+(n-2) h^{2}}\left(\mathrm{~F}_{\mathrm{D}}-\mathrm{F}_{\mathrm{S}}\right)+ \\
\frac{h^{2}\{n(\mathrm{I}+d)+2\}}{4+\{n(\mathrm{I}+d)-2\} h^{2}}\left(\mathrm{~F}_{\mathrm{S}}-\mathrm{P}\right)
\end{aligned}
$$

TABLE 3

Weighting coefficients for index of selection

\begin{tabular}{|c|c|c|c|c|c|c|c|c|}
\hline \multirow{2}{*}{$d$} & \multicolumn{4}{|c|}{$h^{2}=0.05$} & \multicolumn{4}{|c|}{$h^{2}=0.10$} \\
\hline & $n=2$ & 4 & 6 & 8 & $n=2$ & 4 & 6 & 8 \\
\hline $\begin{array}{r}2 \\
4 \\
6 \\
8 \\
10 \\
12 \\
14 \\
16\end{array}$ & $\begin{array}{r}b_{2}=0.950 \\
b_{3}=1 \cdot 764 \\
3.368 \\
4.833 \\
6.175 \\
7.410 \\
8.233 \\
8 \cdot 943 \\
9.561\end{array}$ & $\begin{array}{r}\text { I } \cdot 854 \\
3 \cdot 2 \text { I } 3 \\
5 \cdot 90 \text { I } \\
8 \cdot 184 \\
\text { I } 0 \cdot 146 \\
\text { I I } \cdot 85 \text { I } \\
\text { I } 3 \cdot 346 \\
\text { I } 4 \cdot 668 \\
\text { I } 5 \cdot 845\end{array}$ & $\begin{array}{r}2.714 \\
4.411 \\
7.841 \\
10.586 \\
12.832 \\
14.702 \\
16.286 \\
17.643 \\
18.819\end{array}$ & $\begin{array}{r}3 \cdot 534 \\
5 \cdot 406 \\
9 \cdot 341 \\
12 \cdot 346 \\
14.705 \\
16 \cdot 610 \\
18 \cdot 179 \\
19 \cdot 495 \\
20 \cdot 615\end{array}$ & $\begin{aligned} b_{2}= & 0.900 \\
b_{3}= & 1.555 \\
& 2.850 \\
& 3.946 \\
& 4.886 \\
& 5.700 \\
& 6.413 \\
& 7.041 \\
& 7.600\end{aligned}$ & $\begin{array}{l}1 \cdot 714 \\
2 \cdot 606 \\
4 \cdot 493 \\
5 \cdot 922 \\
7 \cdot 042 \\
7 \cdot 944 \\
8 \cdot 686 \\
9 \cdot 306 \\
9 \cdot 833\end{array}$ & $\begin{array}{r}2 \cdot 455 \\
3 \cdot 331 \\
5 \cdot 487 \\
6 \cdot 995 \\
8 \cdot 111 \\
8 \cdot 969 \\
9 \cdot 649 \\
10 \cdot 202 \\
10 \cdot 660\end{array}$ & $\begin{array}{r}3 \cdot 130 \\
3.837 \\
6 \cdot 100 \\
7 \cdot 593 \\
8.651 \\
9 \cdot 441 \\
10.053 \\
10.540 \\
10.939\end{array}$ \\
\hline & \multicolumn{4}{|c|}{$h^{2}=0.020$} & \multicolumn{4}{|c|}{$h^{2}=0.30$} \\
\hline $\begin{array}{r}2 \\
4 \\
6 \\
8 \\
10 \\
12 \\
14 \\
16\end{array}$ & $\begin{aligned} b_{2}= & 0.800 \\
b_{3}= & 1 \cdot 200 \\
& 2 \cdot 057 \\
& 2 \cdot 700 \\
& 3.200 \\
& 3 \cdot 600 \\
& 3.930 \\
& 4.200 \\
& 4.431\end{aligned}$ & $\begin{array}{l}I \cdot 455 \\
I \cdot 745 \\
2 \cdot 756 \\
3 \cdot 415 \\
3 \cdot 879 \\
4 \cdot 235 \\
4 \cdot 488 \\
4 \cdot 699 \\
4 \cdot 871\end{array}$ & $\begin{array}{l}2 \cdot 000 \\
2 \cdot 000 \\
3 \cdot 000 \\
3 \cdot 600 \\
4 \cdot 000 \\
4 \cdot 286 \\
4 \cdot 500 \\
4 \cdot 666 \\
4 \cdot 800\end{array}$ & $\begin{array}{l}2 \cdot 462 \\
2 \cdot 110 \\
3 \cdot 056 \\
3 \cdot 593 \\
3 \cdot 938 \\
4 \cdot 180 \\
4 \cdot 358 \\
4 \cdot 495 \\
4 \cdot 603\end{array}$ & $\begin{aligned} b_{2}= & 0 \cdot 700 \\
b_{3}= & 0 \cdot 915 \\
& 1 \cdot 488 \\
& 1 \cdot 879 \\
& 2 \cdot 164 \\
& 2 \cdot 380 \\
& 2 \cdot 550 \\
& 2 \cdot 687 \\
& 2 \cdot 800\end{aligned}$ & $\begin{array}{l}I \cdot 217 \\
I \cdot 183 \\
1 \cdot 76 \text { I } \\
2 \cdot 105 \\
2 \cdot 332 \\
2 \cdot 493 \\
2 \cdot 614 \\
2 \cdot 708 \\
2 \cdot 783\end{array}$ & $\begin{array}{l}I \cdot 61 \bar{J} \\
I \cdot 248 \\
I \cdot 772 \\
2 \cdot 060 \\
2 \cdot 242 \\
2 \cdot 367 \\
2 \cdot 459 \\
2 \cdot 529 \\
2 \cdot 585\end{array}$ & $\begin{array}{l}I \cdot 931 \\
I \cdot 238 \\
I \cdot 705 \\
I \cdot 950 \\
2 \cdot 101 \\
2 \cdot 203 \\
2 \cdot 277 \\
2 \cdot 333 \\
2 \cdot 377\end{array}$ \\
\hline
\end{tabular}

$\mathbf{I}=(\mathbf{P}-\overline{\mathbf{P}})+b_{2}\left(\mathrm{~F}_{\mathbf{D}}-\overline{\mathbf{P}}\right)+b_{3}\left(\mathrm{~F}_{\mathrm{S}}-\overline{\mathrm{P}}\right)$

Although statistical derivation from first principles is more complex, the practical application of this formula is simpler when all quantities are expressed as deviations from the population mean. Equation (F) may be adjusted to give

$$
\begin{aligned}
\mathrm{I}=\frac{h^{2}}{2-h^{2}}(\mathrm{P}-\overline{\mathrm{P}})+\frac{h^{2}}{2-h^{2}} & \frac{2 n\left(\mathrm{I}-h^{2}\right)}{4+(n-2) h^{2}}\left(\mathrm{~F}_{\mathrm{D}}-\overline{\mathrm{P}}\right)+ \\
& \frac{h^{2} 4 n d\left(\mathrm{I}-h^{2}\right)}{\left\{4+(n-2) h^{2}\right\}\left\{4+[n(\mathrm{r}+d)-2] h^{2}\right\}}\left(\mathrm{F}_{\mathrm{S}}-\overline{\mathrm{P}}\right)
\end{aligned}
$$


or, since only the relative weights are important in selection,

$$
\begin{aligned}
\mathbf{I}=(\mathbf{P}-\overline{\mathrm{P}})+\frac{2 n\left(\mathrm{I}-h^{2}\right)}{4+(n-2) h^{2}}\left(\mathbf{F}_{\mathrm{D}}-\overline{\mathrm{P}}\right)+ \\
\\
\overline{\left\{4+(n-2) h^{2}\right\}\left\{4+[n(\mathrm{I}+\bar{d})-2] h^{2}\right\}}\left(\mathbf{F}_{\mathrm{S}}-\overline{\mathrm{P}}\right) .
\end{aligned}
$$

As a check, when $n=\mathrm{I}$ the individual value and full-sib average are identical and the case corresponds to combination selection on individual record and half-sib average. $(\mathrm{G})$ reduces to

$$
\mathbf{I}=\frac{3\left(2-h^{2}\right)}{4-h^{2}}(\mathbf{P}-\overline{\mathbf{P}})+\frac{4 d\left(\mathbf{I}-h^{2}\right)\left(2-h^{2}\right)}{\left(4-h^{2}\right)\left\{4+(d-\mathbf{I}) h^{2}\right\}}\left(\mathbf{F}_{\mathrm{s}}-\overline{\mathbf{P}}\right)
$$

where the ratio of coefficients is $4 d\left(\mathbf{I}-h^{2}\right) / 3\left\{4+(d-\mathbf{I}) h^{2}\right\}$. This may be independently obtained from the formula of Lush (1947, p. 257) as $d(r-t) /(\mathrm{I}-r)\{\mathrm{I}+(d-\mathbf{I}) t\}$ where $r=\frac{1}{4}$ and $t=\frac{1}{4} h^{2}$.

Likewise if $d=\mathrm{I}, \mathrm{F}_{\mathrm{D}}$ and $\mathrm{F}_{\mathrm{S}}$ are synonymous, corresponding to full-sib selection with unrelated families,

$$
\mathrm{I}=(\mathbf{P}-\mathbf{P})+\frac{2 n\left(\mathrm{I}-h^{2}\right)}{2+(n-\mathrm{I}) h^{2}}\left(\mathrm{~F}_{\mathrm{D}}-\mathbf{P}\right) \text {. }
$$

The ratio $2 n\left(\mathbf{I}-h^{2}\right) /\left\{2+(n-\mathbf{I}) h^{2}\right\}$ is similarly derived from Lush's formula and corresponds to the weight for family average in full-sib selection provided the half-sib relationship of families can be neglected.

Formula $(G)$ is of course applicable for all values of heritability. As expected, the weight attached to $F_{\mathrm{S}}$ is large for low values of $h^{2}$ for which the superiority of sire family selection has been demonstrated. Regarding now $P, F_{S}$ and $F_{D}$ as deviations from means, the function, for $h^{2}=0.05, n=6, d=10$, becomes $\mathrm{I}=\mathrm{P}+2.714 \mathrm{~F}_{\mathrm{D}}+14.702 \mathrm{~F}_{\mathrm{S}}$ : In spite of the fact that with increasing $h^{2}$ sire family selection soon becomes less efficient than full-sib selection and eventually less efficient than individual selection, the major importance of the sire average when combined with individual values and full-sib averages extends to quite high values of $h^{2}$. At $h^{2}=0 \cdot 25, n=6, d=\mathrm{I} 0, \mathrm{I}=\mathrm{P}+\mathrm{I} \cdot 80$ $\mathrm{F}_{\mathrm{D}}+3 \cdot 15 \mathrm{~F}_{\mathrm{S}}$. Even at $h^{2}=0.50$ the function, for $n=2$ and $d=16$, is $\mathrm{I}=\mathrm{P}+0.50 \mathrm{~F}_{\mathrm{D}}+\mathrm{I} \cdot 20 \mathrm{~F}_{\mathrm{S}}$. However, as expected and as illustrated later, the relative gain in efficiency of the function becomes smaller with increased heritability and for poultry its main utility will be for values less, say, than $0 \cdot 30$. Table 3 gives the appropriate weights for $n$ between 2 and 8, $d$ between 2 and 16 and $h^{2}=0.05,0.10,0.20$ and $0 \cdot 30$, whilst fig. 6 illustrates the variation in weighting factors with heritability for an average case $n=6$.

One important restriction in the use of these weights is for varying family size. For the simpler single type family classification as discussed by Lerner and Lush, e.g. full-sib families of size $n$, different weights can be applied to families of varying size, the regressions being regarded as those obtained in hypothetical populations of family 
size $n_{1}, n_{2}$ and so on. Each family is thus given weights appropriate to its own value of $n$. For the case discussed here the comparable situation is that each sire family may be assigned weights according to its value of $d$, but the results are derived on the assumption that $n$, within a sire group, is constant. It is doubtful that serious errors will arise by replacing $n$ by its average value within a particular sire group unless marked variation is present, but the problem is subject to further investigation.

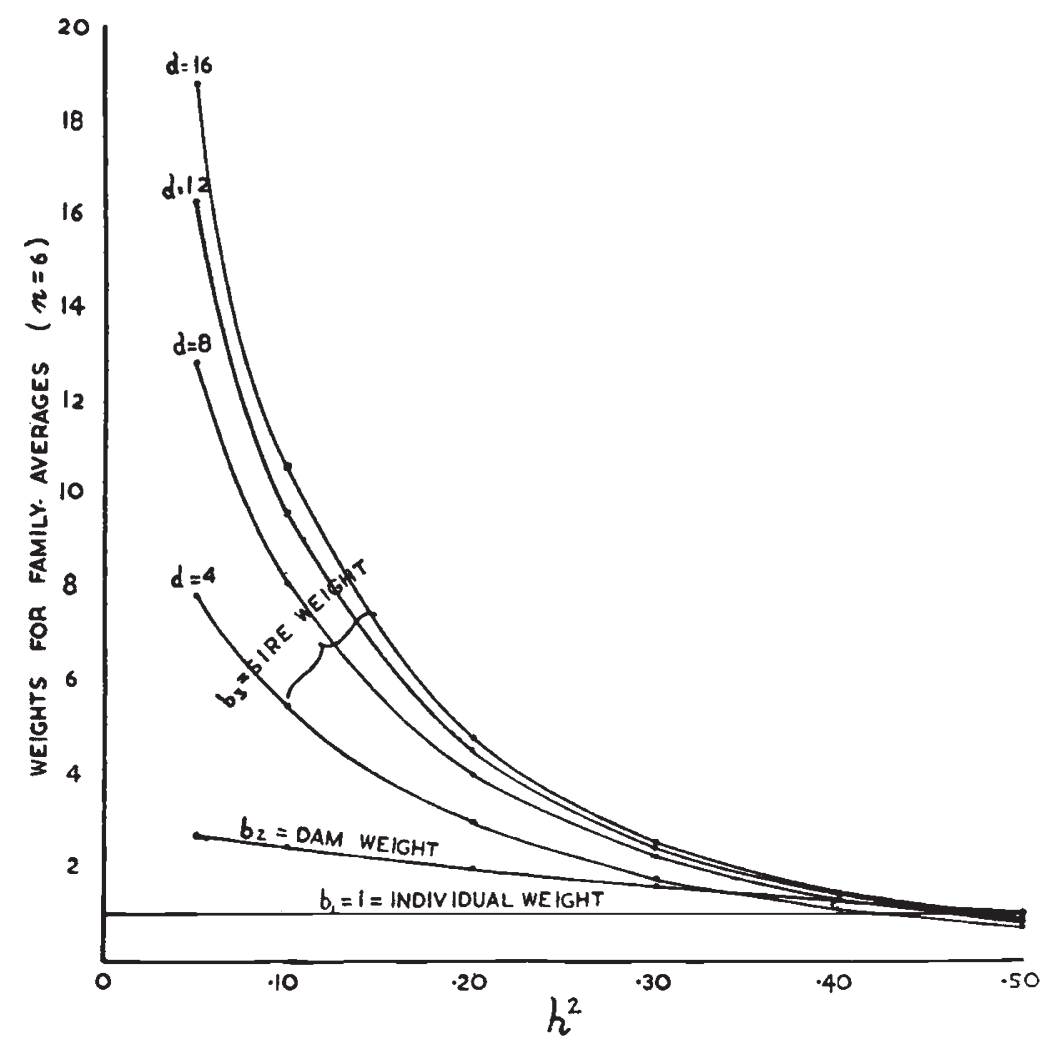

Fig. 6.-Weighting factors for individual performance $\left(b_{1}=1\right)$, full-sib average $\left(b_{2}\right)$, and sire family average $\left(b_{3}\right)$, when the full-sib families are of size $6, h^{2}=0$ to 0.50 .

Relative efficiency of system (4). The gain from selection on an index $\mathrm{I}$ is $\Delta \mathrm{G}_{\mathrm{I}}=\frac{1}{2} \mathrm{R}_{\mathrm{IG}} h \sigma_{\mathrm{P}}$ so that $\mathrm{R}_{\mathrm{IG}} / h$ measures the efficiency relative to that of individual selection.

For multiple regression of genotype $\mathrm{G}$ on the mutually independent factors $\left(P-F_{D}\right),\left(F_{D}-F_{S}\right)$ and $\left(F_{S}-\bar{P}\right)$ the multiple correlation coefficient $R$ is defined by

$$
\mathbf{R}^{2}=b_{1}{ }^{2} \frac{\sigma_{1}{ }^{2}}{\sigma_{G}^{2}}+b_{2}{ }^{2} \frac{\sigma_{2}^{2}}{\sigma_{G}^{2}}+b_{3}{ }^{2} \frac{\sigma_{3}{ }^{2}}{\sigma_{G}^{2}}
$$

where $b_{1}, b_{2}$ and $b_{3}$ are the regression coefficients on the three variables respectively and $\sigma_{1}{ }^{2}, \sigma_{2}{ }^{2}, \sigma_{3}{ }^{2}$ are the variances of the three variables. 
As in the previous section

$$
\begin{gathered}
b_{1}=h_{1}{ }^{2}=\frac{h^{2}}{2-h^{2}} ; b_{2}=h_{2}{ }^{2}=\frac{h^{2}(n+2)}{4+(n-2) h^{2}} ; \\
b_{3}=h_{3}{ }^{2}=\frac{h^{2}\{n(\mathrm{I}+d)+2\}}{4+\{n(\mathrm{I}+d)-2\} h^{2}} ; \\
\sigma_{1}{ }^{2}=\frac{n-\mathrm{I}}{n} \cdot \sigma_{\mathrm{P}}{ }^{2} \frac{\left(2-h^{2}\right)}{2} ; \sigma_{2}{ }^{2}=\frac{d-\mathrm{I}}{d} \cdot \sigma_{\mathrm{P}}^{2} \frac{\left\{4+(n-2) h^{2}\right\}}{4^{n}} ; \\
\sigma_{3}{ }^{2}=\frac{s-\mathrm{I}}{s} \cdot \sigma_{\mathrm{P}}{ }^{2} \frac{\left\{4+[n(\mathrm{I}+d)-2] h^{2}\right\}}{4 d n} .
\end{gathered}
$$

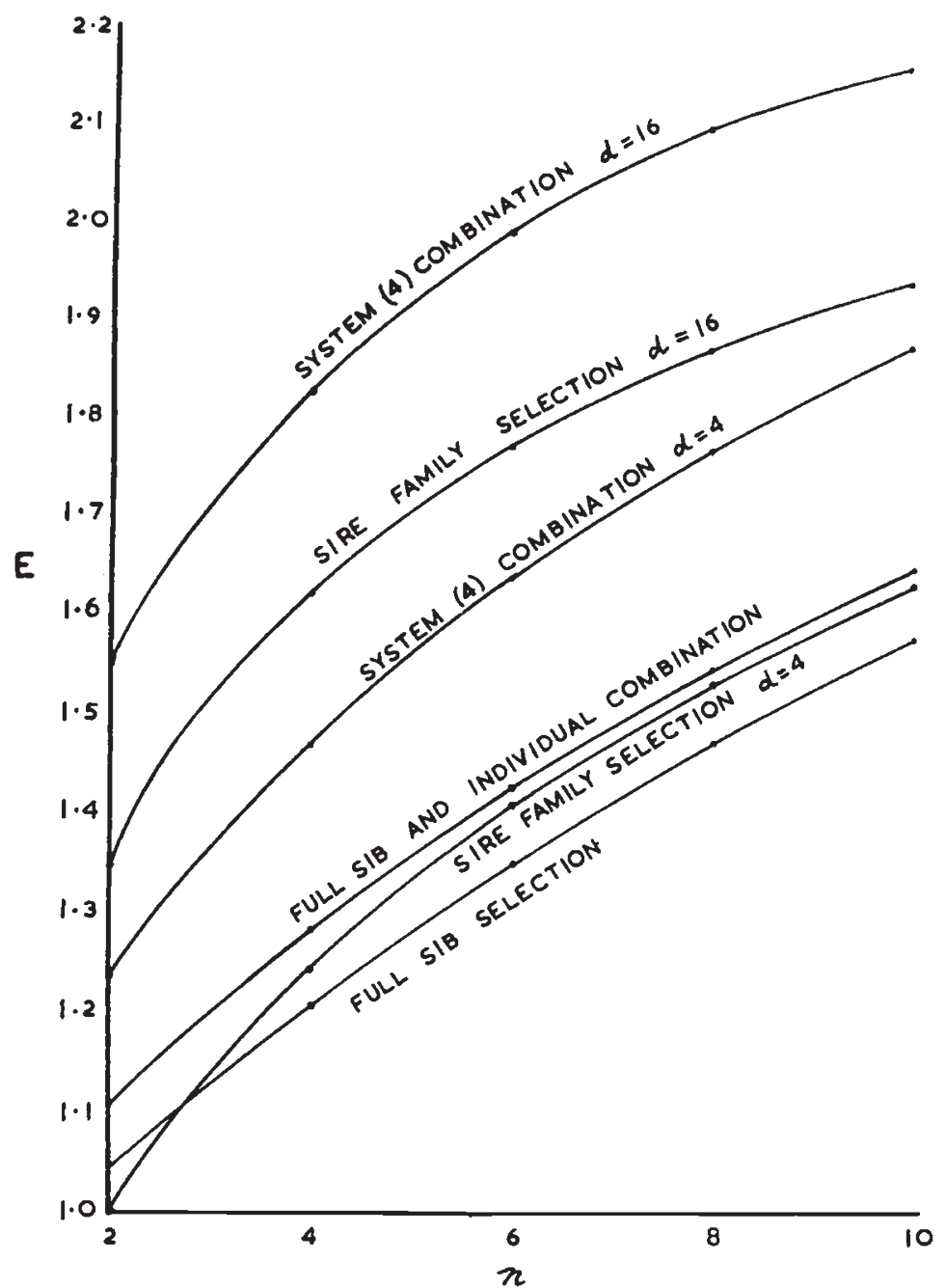

FIG. 7.-Efficiencies of all systems ( 1 ) to (4) relative to that of individual selection $\left(h^{2}=0 \cdot 05\right)$.

Assuming, as before, the number of sires to be large, the factor $(s-\mathrm{I}) / \mathrm{s}$ can be ignored, giving on substitution and simplification, the efficiency 
relative to individual selection as

$$
\begin{aligned}
\frac{\mathrm{R}}{h}=\left[\frac{n-\mathrm{I}}{n} \cdot \frac{\mathrm{I}}{2\left(2-h^{2}\right)}+\frac{(d-\mathrm{I})}{d} \cdot \frac{(n+2)^{2}}{4 n\left\{4+(n-2) h^{2}\right\}}+\right. \\
\left.\frac{\{n(\mathrm{I}+d)+2\}^{2}}{4 d n\left\{4+[n(\mathrm{I}+d)-2] h^{2}\right\}}\right]^{\frac{1}{2}}
\end{aligned}
$$

As a check, if $d=\mathrm{I},(\mathrm{H})$ reduces to

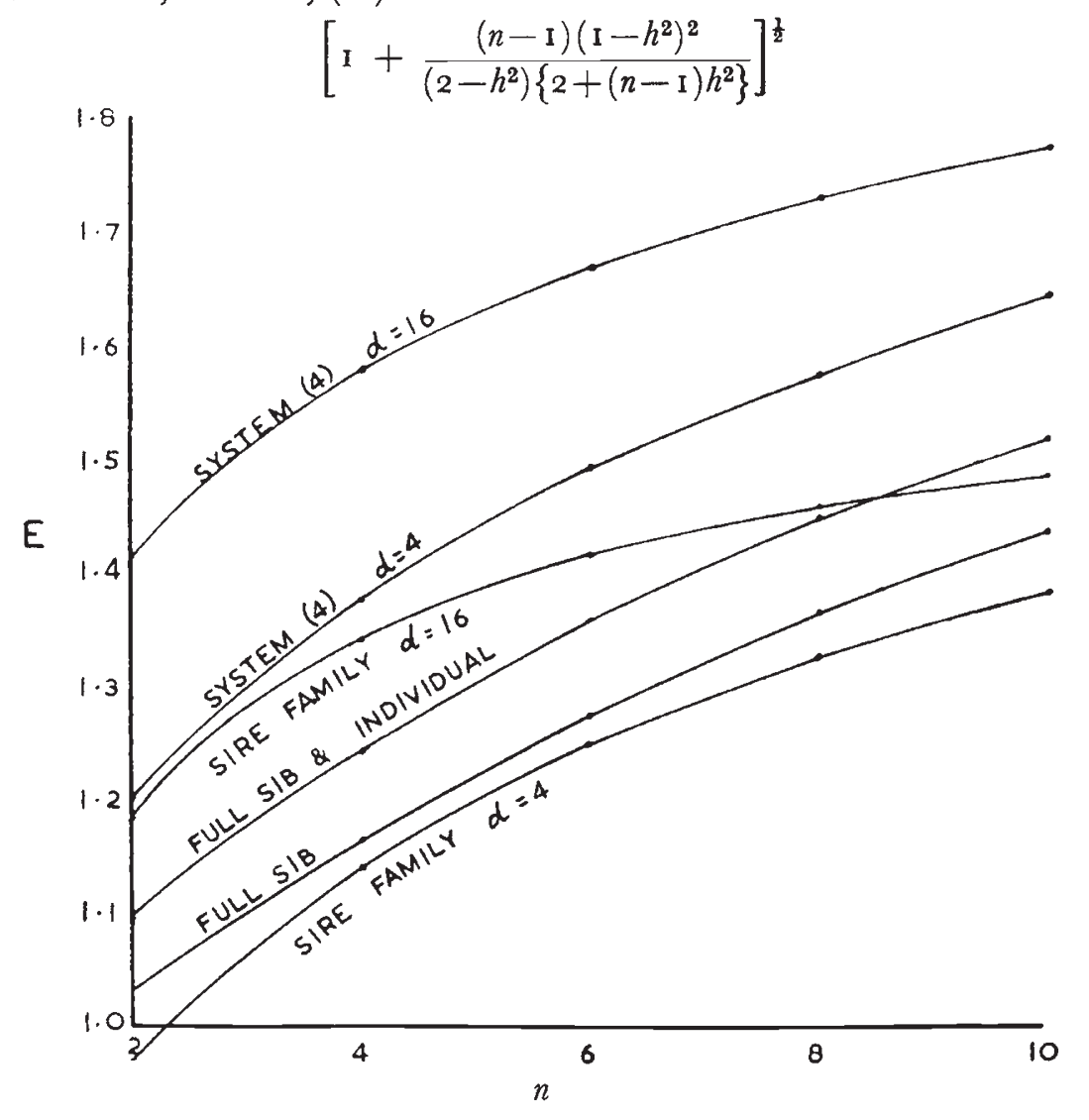

FIG. 8. -As fig. 9 for $h^{2}=0 \cdot 10$.

given by Lerner (p. 2I8) for combination selection on individual record and unrelated full-sib family averages. Similarly the correct result for combination of individuals and half-sib families may be obtained by putting $n=\mathrm{I}$.

Figs. 7 and 8 show the relative efficiencies of all systems (I) to (4) for $h^{2}=0.05$ and $h^{2}=0.10$ and the superiority of combination selection on system (4) over any of the others, particularly for large $d$, is evident. A typical example of the relative efficiencies for $n=6$, $d=16, h^{2}=0.05$, taking the gain from individual selection as ro units, is

(I) Full-sib selection : I 3.5 ; 
(2) Combination selection on full-sib average and individual record : $14 \cdot 25$;

(3) Sire family selection : $17 \cdot 7$;

(4) Combination selection on full-sib average, sire-family average and individual record : $19 \cdot 8$.

A striking feature is that whilst system (2) may give little advantage over system (I), the gain in efficiency of systems (3) and (4) over (2)

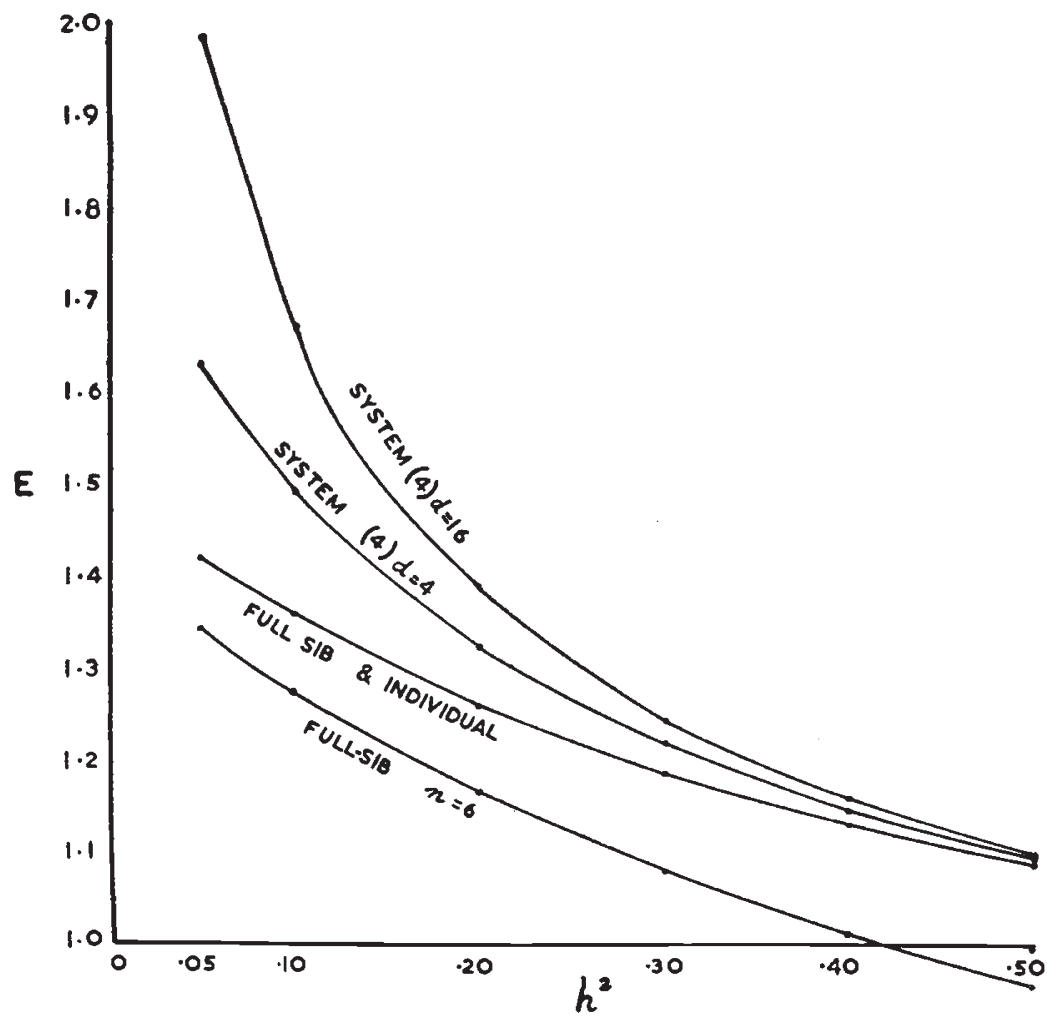

FIG. 9.-Efficiencies of systems (I), (2) and (4) relative to individual selection when full-sib families are of size $6, h^{2}=0$ to 0.50 .

may be quite considerable, and likewise the gain from (4) over the gain from (3).

Fig. 9 shows, for an average case $n=6$, and all values of $h^{2}$ up to 0.50 , the relative efficiency of systems (I), (2) and (4), the latter for $d=4$ and $d=\mathrm{r} 6$. The advantage of system (4) over the others declines with increasing heritability, as does the advantage of each system over individual selection, but for the range applicable to many production traits, it is clear that worthwhile improvements may be obtained by judicious consideration of family average and individual record. In the important case where recording facilities are limited, something approaching maximum efficiency may be obtained by consideration of the sire family average alone. 


\section{SUMMARY}

I. Systems of family selection or selection on a combination of family merit and individual merit are discussed for a population where, as in poultry, the family classification is a hierarchical one, consisting of offspring from several sires each mated to several dams. Four methods are compared with each other and with individual selection, the comparisons referring to selection of females in a population of females as in poultry :

(a) Selection of complete full-sib families disregarding individual merit or classification into half-sib families.

(b) Selection on the basis of an index with particular weights attached to full-sib family averages and to individual records.

(c) Selection of complete sire families, each family consisting of a mixture of full- and half-sibs.

(d) Selection on an index with particular weights attached to sire family averages, dam family averages, and individual records.

2. Systems $(a)$ to $(c)$ may be regarded as particular cases of $(d)$ and it is axiomatic that the latter provides greatest efficiency. A general formula is derived giving appropriate weighting factors for all values of heritability and distributions of offspring by families, and these are tabulated for particular cases. For low values of heritability in particular, marked increases in efficiency are obtainable and even up to high values (subject to restrictions imposed by the distribution of offspring), greatest weight is to be attached to sire family average, less weight to dam family average, and least of all to individual performance.

3. For low values of heritability, system (c), selection of sire families alone, may be markedly more efficient than individual selection or family and combination selection on systems $(a)$ and $(b)$. This feature may prove of major importance in populations where trapnesting or individual recording facilities are limited. Provided the intervention of environmental effects can be neglected (as some published evidence would indicate) selection for production traits with low heritabilities such as egg production may be based on sire family averages alone, each family being housed as a unit without individual recording.

4. Apart from complications introduced by extension of the breeding season maximum gains from systems $(c)$ and $(d)$ may be obtained by selecting the minimum number of breeding females necessary to replace the population, and maximising the number of dams mated to a given sire. Whilst these gains are referred to selection of females alone it is evident that all effects are cumulative since this procedure provides a higher possible selection pressure on male parents. Greater gains from selection, at least for low values of 
heritability are possible in larger populations providing the difference in population size is due only to the number of dam families in a sire group.

5. Corrections are given for the orthodox expectation of gain from individual and family selection when small populations are involved.

Acknowledgment.-The writer expresses his appreciation to Dr A. Robertson for his helpful suggestions and critical appraisal of the manuscript.

\section{REFERENCES}

ANDERSON, R. L., AND BANCROFT, T. L. 1952. Statistical Theory in Research. New York : McGraw-Hill.

COMSTOCK, R. E., AND RoBINSON, H. F. I 948. The components of genetic variance in populations of bi-parental progenies and their use in estimating the average degree of dominance. Biometrics, 4, 254-266.

DEMPSTER, E. R., AND LERNER, I. M. I947. The optimum structure of breeding flocks. I. Rate of genetic improvement under different breeding plans. Genetics, $32,555-566$.

DUDLEY, F. J., AND READ, D. R. I949. The design of experiments in egg production of poultry. Harper Adams Util. Poult. 7., 34, 65 .

FISHER, R. A. I9r8. The correlations between relatives on the supposition of Mendelian inheritance. Trans. Roy. Soc. Edin., 52, 399-433.

Fisher, R. A., AND yates, F. 1948. Statistical Tables for Biological, Agricultural and Medical Research. 3rd Ed. Edinburgh : Oliver and Boyd.

GARBER, M. J., AND GODBEY, C. B. I952. The influence of sire, dam and hatching date on specific rate of growth of single comb White Leghorn pullets from hatching to twelve weeks of age. Poult. Sci., 31, 945-955.

Hagedoorn, A. L., AND sykes, G. 1953. Poultry Breeding. London : Crosby Lockwood and Son.

Hale, R. W. 1952. Experimental errors in laying experiments. 7. Agric. Sci., 42, 347-352.

HALE, R. W. 1954. Heritability of chick viability in a White Wyandotte flock. 7. Agric. Sci., 44, 22 I-226.

HAZEL, L. N. 1943. The genetic basis for constructing selection indexes. Genetics, $28,476-490$.

HUtт, F. B. 1952. The Jansen Khaki Campbell ducks. 7. Hered., 43, 277-28 r.

Jull, M. A. 1952. Poultry Breeding. 3rd Ed. New York: Wiley and Sons.

KING, S. C., AND HENDERSON, C. R. I954. Heritability studies of egg production in the domestic fowl. Poult. Sci., 33, I55-169.

LERner, I. M. I950. Population Genetics and Animal Improvement. Cambridge University Press.

LERNER, I. M., AND HAZEL, L. N. 1947. Population genetics of a poultry flock under artificial selection. Genetics, 32, 325-339.

Lush, J. L. 1945. Animal Breeding Plans. 3rd Ed. Ames, Iowa : Collegiate Press. LUSH, J. L. 1947. Family merit and individual merit as bases for selection. Amer. Nat., $8 \mathrm{I}, 24 \mathrm{I}-26 \mathrm{I}, 362-379$.

LUSH, J. L., LAMOREUX, W. F., AND HAZEL, L. N. I948. The heritability of resistance to death in the fowl. Poult. Sci., 27, 375-388.

NORDSKog, A. W., AND WYATT, A. J. 1952. Genetic improvement as related to size of breeding operations. Poult. Sci., 3I, r 062-1066.

OSBORNE, R. 1952. Sexual maturity in Brown Leghorns: the interactions of genotype and environment. P.R.S. Edin. B, 64, 445-455.

osborne, R. 1954a. Sexual maturity in Brown Leghorns and the relationship of genetic variance to differences in environment. P.R.S. Edin. B, 65, 285-298. 
OSBORNE, R. 1954b. Inheritance studies on egg weight in the domestic fowl. Off. Rep. Xth World's Poult. Congr. (Edin.), pp. 33-37.

ROBERTSON, A. 1955. Prediction equations in quantitative genetics. Biometrics, II , 95-98.

ROBERTSON, A., AND LERNER, ז. M. 1949. The heritability of all-or-none traits : viability in poultry. Genetics, 34, 395-41 I.

SKALLER, F., AND SHELDON, B. L. 1955. Interactions of genotype and environment in determining sexual maturity in the domestic fowl. Austral. F. Agric. Res., $6,171-185$.

sykes, G. 1953. Practical problems in the progeny testing of poultry. Proc. Brit. Soc. Animal Prod., 1953, pp. 61-75.

WRIGHT, s. 1921. Systems of mating. Genetics, 6, I I I-1 78. 